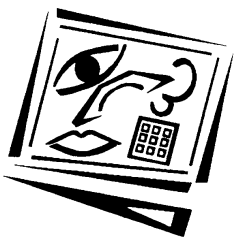

\title{
E-learning in context: An assessment of student inequalities in a university outreach program
}

\author{
Nicole Crawford \\ University of Tasmania \\ Lara McKenzie \\ The University of Western Australia
}

\begin{abstract}
E-learning technologies are often seen as a driving force in the democratisation of contemporary education. However, few researchers have focused on inequalities in online learners' access to technologies or their abilities to use them. In 2009, we assessed The University of Western Australia's SmARTS outreach program, investigating the advantages and disadvantages of employing online learning in the local context of Perth, Western Australia. SmARTS uses blended learning techniques, combining both online and face to face methods. However, our discussion here is based primarily on the online component. Our research methods included the collection of 52 student surveys, a group interview with the 2009 tutors, and our own observations and experiences. Our findings suggested that students were not particularly savvy with technology, in contrast to the common assumption. We also found that the location of students' residences and the types of schools they attended had an impact on their self-assessed online participation, the reliability and speed of their Internet connections, and their confidence and ease with using computers and the Internet. Our findings revealed that the social inequalities present in the context of Perth had an impact on whether students were advantaged or disadvantaged by the online component of SmARTS.
\end{abstract}

\section{Introduction}

There are numerous widespread assumptions underpinning contemporary research into e-learning. Academic and popular opinions tend to reflect a belief in technological determinism, which claims that technologies determine "social and cultural trends and patterns" (Rettberg, 2008, p.52). Technological determinists assume that the local contexts in which technologies are produced and consumed have a minimal impact on their outcomes (Postman, 1993, pp.7, 18; Sassen, 2004, p.78). The rhetoric surrounding e-learning tends to reflect this belief, and many discussions of technology in education focus primarily on the capabilities, limitations, and evolution of technologies (Pegrum, 2009 , p.5). However, some e-learning researchers have begun to address the variable contexts in which these technologies are formed, and the impact that local contexts can have on their uses and outcomes (Anderson, 2005; Clegg, Hudson \& Steel, 2003; Kennedy, Judd, Churchward \& Gray, 2008). Furthermore, while some theorists claim that e-learning has the potential to democratise education, others state that the social inequalities which have been historically present in educational institutions are now being reflected in online learning (Carr-Chellman, 2005b, p.1; Hargittai, 2002). 
In this paper we argue for the importance of examining local contexts, particularly local inequalities, when applying online learning methods. In 2009, we took SmARTS as a case study. SmARTS is an outreach program for year 11 high-school students (age 15-16 years) living throughout the Perth Metropolitan area, which is run at The University of Western Australia (UWA). SmARTS employs blended learning techniques, combining both face to face and online learning methods. However, our discussion here is primarily about the online component of SmARTS. Our findings are based on student surveys, a group interview with the tutors, and our own observations and experiences as tutors.

SmARTS is an initiative of the Faculty of Arts, Humanities and Social Sciences (Arts Faculty) at UWA. It has been running since 2001, and is a six-month program conducted between March and September of each year. It divides year 11 students from a number of high schools into small groups, consisting of around eight individuals. Each group completes a written research project throughout the year, and the program culminates with a Presentation Night, at which the groups present their research findings to an audience of teachers, parents and judges. The group research projects focus on topics within the humanities and social sciences (for further information about SmARTS, see http:/ / www.arts.uwa.edu.au/community/smarts). As many of the students involved in the SmARTS program live in areas extremely far from UWA, up to one and a half hours away, it is impractical for them to travel this distance every week. Therefore, groups meet on campus approximately once a month, at a time that is negotiated between the students and their tutors. The most frequent interactions between the students and their tutors, however, occur online, where students complete weekly tasks related to their projects. SmARTS is therefore a useful case study for exploring e-learning in context.

SmARTS takes place in Perth, Western Australia, which in 2009 had approximately $1,660,000$ residents (ABS, 2010, Table 5). Perth is a relatively sprawled city, covering 5,386 square kilometres (ABS, 2010, Table 5). In 2009, it had the third lowest population density of all Australian State and Territory capitals: 308 persons per square kilometre (ABS, 2010, Table 5). Perth residents have minimal access to free wireless broadband connections, and therefore access to the Internet is strongly influenced by one's location of residence. Statistics gathered between 2008 and 2009 show that almost two thirds, or 62 percent, of Australian households have a broadband connection, and that this is increasing (ABS, 2009, p.1). In spite of this increase, there is still a significant proportion of the population who do not have access to a home broadband connection. Thus, when implementing blended learning or e-learning models in Perth, it is important to recognise that some students may have slow or unreliable Internet connections.

In 2009, SmARTS employed several technologies. Each group had access to their own blog, on which students were able to post messages, images, and documents. The blogs were linked to the University's learning management system, WebCT. Through WebCT, groups also had access to their own discussion board and chat room. However, the primary e-learning technology that was used by students was their group's blog; email was often used when communication was unsuccessful on the blog or WebCT discussion board. Each student was required to enter different usernames and passwords in order to access their WebCT account, their blog, and their chat room. This inefficient process created many problems for both students and tutors. 


\section{A background to e-learning and inequality}

E-learning, or electronic learning, carries with it various advantages and disadvantages (Liu \& Hwang, 2009, p.1). Purported advantages include increased flexibility, the ability to overcome great physical distances between students and educational institutions, and the possible self-determination of student learning (Liu \& Hwang, 2009). However, possible disadvantages include decreased face-to-face interaction, as well as differential access between students based on socioeconomic status, gender, age, and other factors. These advantages and disadvantages might be expected to vary considerably between different local contexts. It is therefore important to consider how global, local, historical, cultural, social, and individual factors might impact on how e-learning and blended learning play out.

Emphasising the advantages of e-learning, numerous scholars and politicians claim that new media technologies will bring about the increased democratisation of knowledge and more widespread access to information (Pegrum, 2009). However, in reality it remains unclear as to whether e-learning has any potential for democratisation (Carr-Chellman, 2005b). Various studies have shown that factors such as geographic location, socioeconomic status, education, race, language, age, physical ability, and gender all have a significant impact on Internet access and usage (ABS, 2009; Pegrum, 2009; White, Shade \& Brayton, 2001). Even when universal free access is feasible, factors such as motivation and need play a huge part in whether individuals succeed at online learning (Anderson, 2005). As such, it seems that online learning is likely to disadvantage those with lower socioeconomic status (Anderson, 2005). Therefore, as Anderson (2005, p.176) states, "online education does not precede or bring democracy; its effective and universal delivery is conditional on democracy and the political action that occurs within a democracy". It seems that in order for elearning to promote equality, the inequalities which exist in broader society must first be confronted (Carr-Chellman, 2005b). Our own research seeks to identify inequalities between SmARTS students so that we might minimise any difficulties or advantages experienced by them when using e-learning technologies.

\section{The assessment: Background and aims}

Prior to 2009, the online component of SmARTS consisted of weekly meetings in online chat rooms. We observed, however, that students tended to do very little work during these sessions. Furthermore, those with unreliable Internet access were frequently disconnected during these sessions. In 2009, the chat room component was replaced with a blog for each group, enabling students to complete their weekly tasks asynchronously. We hoped that online participation would improve with this change.

In 2009, 40 male and 42 female students took part in SmARTS. Of the schools involved in the program, four were classified as public, or government, and 13 were classified as private, or non-government (Department of Education, 2011). Of the individual students taking part in the program, 71 were from private schools and 11 were from public schools. Thus, the proportions of public and private school students were extremely uneven, while the proportions of male and female students were relatively even.

Our project aimed to explore three areas. Firstly, we sought to uncover the benefits and problems associated with e-learning. In particular, we were concerned with the 
specific issues related to e-learning that exist in the local context of Perth. Secondly, we questioned whether particular types of students were being advantaged by the technologies being used, and whether others were being disadvantaged. We expected to find some differences between students based on their gender, where they lived, and the type of school they attended. Finally, we sought to uncover the extent to which students are "tech-savvy", "tech-comfy", or neither of these. Mark Pegrum (2009, p.43) defines tech-savvy individuals as those who have "a grasp of technology's implications together with the range of digital literacies necessary to use key tools effectively for educational and professional purposes". He describes tech-comfy individuals as those who possess "the technological literacy to use a wide array of digital tools, especially for everyday social and entertainment purposes" (Pegrum, 2009, p.43). Pegrum (2009, p.52) claims that while many young people are "techcomfy", few are "tech-savvy", and some are neither. Based on our observations in previous years, we expected to find our students to be generally tech-comfy, rather than tech-savvy.

In regard to our research focus, it needs to be noted that the areas relating to e-learning that we discuss in this paper (that is, online participation, access, and skills) remain largely separate from the on campus component of SmARTS. We avoid discussing areas that might be influenced by both the online and on campus components, such as students' results or completion rates.

Given that our research focuses on a limited group of secondary school students, our findings should be applied cautiously to the tertiary sector. Although a large proportion of students responding to our surveys expressed an intention to attend university in the future $(73 \%, \mathrm{n}=38)$, intention does not necessarily translate into attendance. Furthermore, even if a high proportion of these students ended up attending university, they are unlikely to be representative of university student populations more generally. This issue highlights our suggestion that universities and schools should consider context when engaging their students in e-learning. Although our research may not be directly applicable to tertiary institutions, it does, however, provide insights into the problems associated with university-based learning management systems.

\section{Research methods}

At the end of the 2009 program, we conducted, firstly, student surveys and, secondly, a group interview with the SmARTS tutors. The surveys and interviews enabled us to identify the challenges, difficulties and benefits that the students experienced when using the online technologies. In addition, we could uncover the ways in which the local conditions of Perth impacted on the students' experiences with the technologies.

Student surveys were distributed by tutors towards the end of the program, but prior to the final Presentation Night. A total of 52 surveys were collected and analysed. The survey consisted of 11 multiple choice or closed answer questions, and 12 open ended questions. The survey asked for background information about students, such as their gender, what school they attended, what suburb they lived in, and how long it took them to travel to UWA. They also responded to questions about their Internet and computer access and skills, how SmARTS could be improved, and their self-assessed attendance and participation levels. The survey was conducted in order to identify areas for improvement, trends in students' experiences, and the strengths and weaknesses of online as opposed to face to face learning. 
Following the end of the program, we interviewed the tutors for 2009. We asked them to discuss their own experiences of online and face to face teaching, as well as their perceptions of their students' experiences with the two modes of learning. Furthermore, we asked if they had noticed any differences between students based on their gender or the schools they attended. Tutors were also asked whether they felt that their students were able to understand and use the technologies effectively. Both authors were also tutors in the 2009 SmARTS program.

\section{Findings and discussion}

\section{Are students tech-savvy?}

E-learning researchers often assume that young people are a homogenous group that possess "a sophisticated knowledge and understanding of information and communication technologies" (Kennedy et al., 2008, p.109). However, Kennedy and colleagues (2009, p.109), who conducted research on first-year university students in Australia, have argued that student populations are diverse in their technological skills. They have also questioned whether students' technological skills "will correspond to skills associated with beneficial, technology based learning" (Kennedy et al., 2008, p.119). Although students may have knowledge of computer technologies, their knowledge is perhaps highly specific and limited to technologies with social and entertainment purposes. This suggestion leads to the question of whether the majority of young people can be considered to be truly tech-savvy, or whether they are techcomfy.

Arguments that claim that young people are tech-savvy tend to find support in statistics on computer and Internet access and usage. Research conducted by the Australian Bureau of Statistics (2009, p.4) between 2008 and 2009 found that household computer and Internet access was significantly above average when a child under the age of 15 was present. On average, 78 percent of households had access to a computer, in comparison with 91 percent of those with children under 15 (ABS, 2009, p.4). The same trend was reflected in Internet access (ABS, 2009, p.4). Furthermore, between 2008 and 2009, those aged from 15 to 17 were the most frequent users of the Internet compared with other age groups (ABS, 2009, p.11). Ninety-four percent of individuals in this age group had used the Internet in the 12 months prior to the survey, while the average rate across all age groups was 74 percent (ABS, 2009, p.11). Thus, it is wellestablished that younger Australians tend to use computers and the Internet more than their older counterparts, and that they have high levels of access to these technologies. The tutors' and our own observations suggest, however, that although students might be very good at using certain technologies, they are not necessarily good at using all technologies, and the vast majority do not have the skills required to tackle technical problems when they arise.

Measuring the technological abilities of students is a difficult task. As we had neither the time nor the resources to test each student's capabilities, we needed to rely on students' self-assessments, tutors' perceptions, and our own observations and experiences. Students' self-assessments showed that the vast majority considered themselves to be relatively confident with computers and the Internet. When asked "how confident do you feel about using computers and the Internet?", 50 percent $(\mathrm{n}=27)$ of students responded that they were always confident, and 48 percent $(\mathrm{n}=24)$ that they were mostly confident. Students were also asked how easy or difficult they 
found the SmARTS blog to use. Here, 38 percent $(n=20)$ responded that it was easy, 54 percent $(\mathrm{n}=28)$ that it was ok, and eight percent $(\mathrm{n}=4)$ that it was difficult. This response reveals that students had some difficulties when using the SmARTS blog, in spite of the fact that the vast majority of them (96\%) stated that they felt confident using computers and the Internet. Thus, the degree to which students are tech-savvy is called into question.

The group interview conducted with tutors revealed that they had little to say about the computer and Internet skills of their students. When asked about their students' abilities using computers and the Internet, one tutor (who we will refer to as Mary)

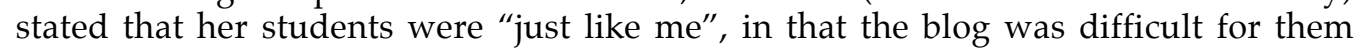
initially, but became more enjoyable once they were familiar with it (personal communication, October 29, 2009). The other tutors seemed to agree with this point, and none of them presented counter-arguments to Mary's claim. The tutors and researchers observed that when students encountered problems with the blog, they tended to give up immediately. Another tutor, who we will call Cathy, stated that, "if they can't figure [the blog] out the first couple of times they just sort of give up" (personal communication, 29 October 2009).

Our own observations suggest that most SmARTS students are tech-comfy, in that they are capable of using numerous digital tools, such as Myspace, Facebook, chat rooms, and MSN Messenger, for entertainment and social purposes. For instance, in the years prior to 2009, when the online component consisted of weekly chat room discussions, tutors reported having great difficulties keeping up with students' conversations, not only in regard to the speed with which they were able to contribute, but also in regard to the abbreviations and slang words which were used by students. Tutors also observed that students often used other online tools whilst engaging in online discussions with their groups. For example, if a group member was absent from the chat room, other students often observed that they were using MSN Messenger, and through this platform they reminded the missing student to join the group discussion.

Although students claimed they had relatively high levels of confidence when using computers and the Internet, they also stated that they had some difficulties when using the SmARTS blog. Tutors' and our own observations also contradicted the common assumption that students today are tech-savvy. However, the question remains as to whether different types of students are more or less likely to be tech-savvy, techcomfy, or neither. For instance, is a students' area of residence, school type, or gender likely to impact on their access to and skills when using computers and the Internet?

\section{Socioeconomic status and student residence}

Socioeconomic status impacts significantly on whether a student has access to a home computer and Internet connection. According to the Household Use of Information Technology survey, between 2008 and 2009, 78 percent of households had home computer access (ABS, 2009, p.4). For households in the highest income quintile, home computer access was significantly higher than average, at 93 percent (ABS, 2009, p.4). For those in the lowest income quintile, home computer access was much lower than average, at 49 percent (ABS, 2009, p.9). These findings were also reflected in Internet access rates (ABS, 2009, p.4). Educational attainment also had an impact on assess and use, with the aforementioned survey showing that highly educated people were more likely to use the Internet (ABS, 2009, p.11). Indeed, research conducted in 2005 
suggested that socioeconomic background and technological literacy are strongly associated amongst school students, with those from lower socioeconomic backgrounds having lower levels of literacy (MCEETYA, 2007, p.63). Follow-up research conducted in 2008 showed that this association has not changed since then (MCEECDYA, 2010, p.42). There is also a strong association between a parent's level of education and their child's computer and Internet access and use (ABS, 2004, pp.14-5).

Furthermore, more affluent suburbs tend to have higher levels of broadband connectivity (ABS, 2008a, p.202). Australian Bureau of Statistics (2006, p.36) data has shown that dwellings in the southeastern part of Perth had the lowest levels of broadband connectivity and that the affluent suburbs of Peppermint Grove, Nedlands, and Cottesloe had the highest. Therefore, statistical evidence shows that use of and access to computers and the Internet, as well as access to a broadband connection, is significantly influenced by one's socioeconomic status.

The survey completed by the students in 2009 did not ask them to provide details of their parents' educational attainment, incomes, and professions. Indeed, it is unlikely that students would have been aware of their parents' incomes. However, we did collect data on students' suburbs of residence, and the reliability and speed of their Internet connections. Our analysis uses the Australian Bureau of Statistics' (2008b, Table 2) Socio-Economic Indexes for Areas (SEIFA) scores for students' suburbs of residence. The SEIFA scores used are the most recently available, and are based on data from the 2006 Census (ABS, 2008b, Table 2). Here, we use the SEIFA measurement of relative socio-economic advantage and disadvantage of suburbs, which takes into account residents' affluence, education, and skills (ABS, 2008b, Table 2). Each suburb is given a numerical value; low values indicate disadvantage and high values indicate advantage (ABS, 2008b, Table 2). We have also compared students using the ABS's (2010, Table 5) division of metropolitan Perth into five areas, which are: central, east, north, southwest, and southeast metropolitan Perth (ABS, 2010, Table 5).

We divided students into four groups, based on the SEIFA scores of their residences. Between these groups, we uncovered differences in students' self-assessed online participation. Figure 1, shown below, shows an unexpected trend. Students in the group with the lowest SEIFA scores $(n=6)$ had by far the highest proportion of individuals claiming that they completed their online tasks regularly $(83 \%)$. The group containing students with the second lowest SEIFA scores $(n=12)$ were far less likely to say that they participated in online tasks regularly (42\% said this), while the group of students with the second highest SEIFA scores $(n=24)$ were even less likely to say that they participated in online tasks regularly (33\% said this). Interestingly, the group containing students with the highest SEIFA scores $(n=10)$ were more likely than the second and third groups to say that they completed their online tasks regularly (50\% said this). A pattern did not emerge for students who said that they completed the online tasks rarely. For those students who claimed to have participated occasionally, none of the students in the group with the lowest SEIFA scores chose this response, while the proportion of students from other groups who chose this response was roughly equal. Thus, it appears that those students who said they participated most regularly were from suburbs with the lowest SEIFA scores. Participation decreased as SEIFA scores increased, and then rose again for the group with the highest SEIFA scores. When comparing students from central, north, east, southeast, and southeast metropolitan areas, there did not appear to be any noticeable trends with regard to self-assessed online participation. 


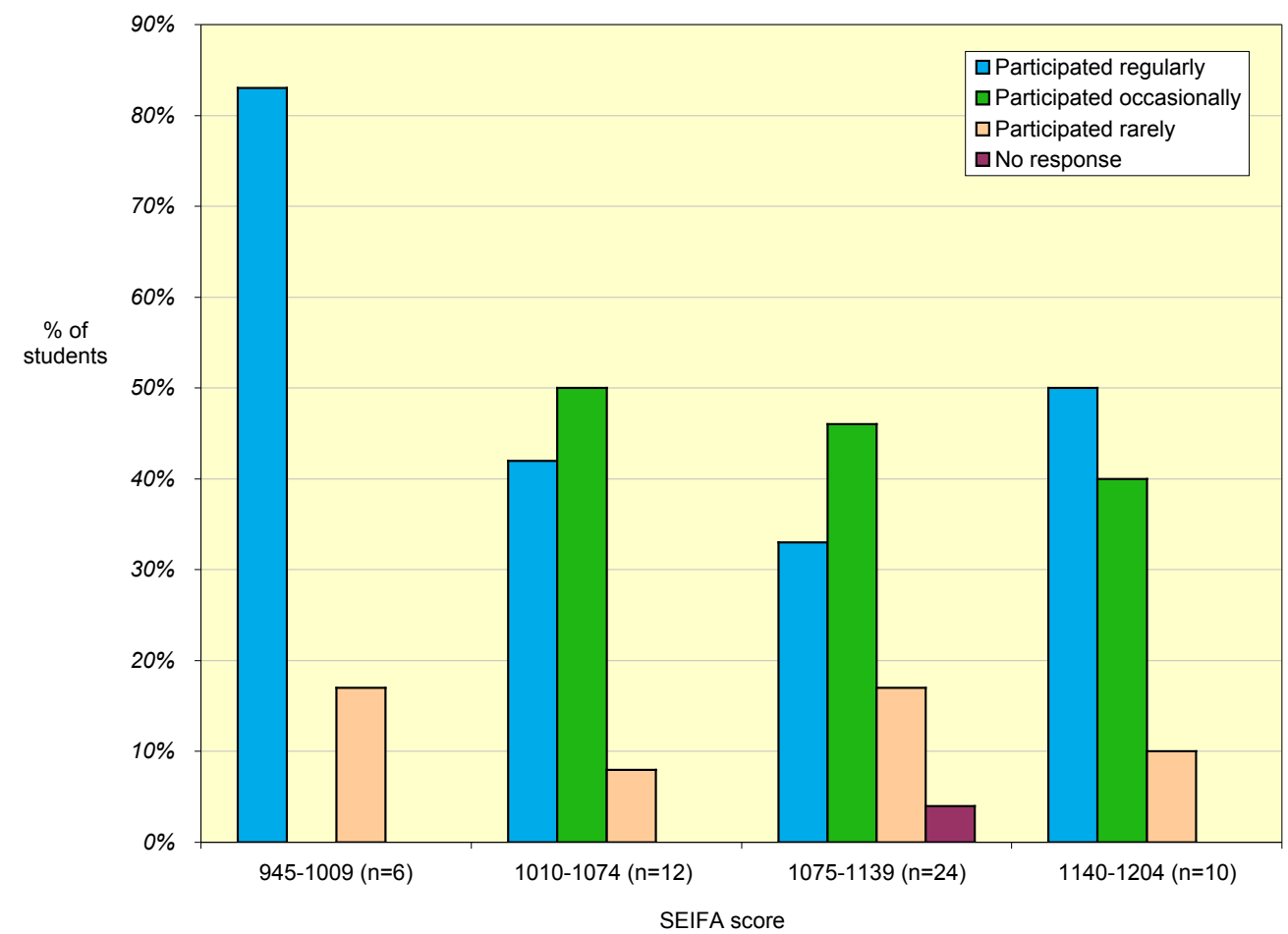

Figure 1: Students' self-assessed online participation by SEIFA score of residence

These findings might be explained by the kinds of students who participate in the SmARTS program. Although students may not necessarily be affluent, SmARTS itself is likely to attract both parents and children who are aspirational, and place a high value on education as a means of achieving upward mobility. Thus, students from lower socioeconomic backgrounds may be more motivated than those from higher ones. SmARTS costs $\$ 660$ per student, or $\$ 330$ for students who receive a scholarship from the Arts Faculty (most of whom attend less affluent schools). It could be the case that students from less affluent backgrounds may place a greater value on being in the program, and may be subjected to higher levels of parental pressure to participate regularly. Finally, it is worth noting that students from less affluent suburbs are numerically fewer, and are therefore probably more likely to be exceptionally highachieving. It is also notable that students' participation is self-assessed, and thus reflects their perceptions rather their actual levels of participation. However, this does not explain why there was a slight increase in online participation amongst students with the highest SEIFA scores, when compared with those with the second and third highest SEIFA scores.

Although we were unaware of the kinds of Internet connections that students had access to at home (that is, broadband or dialup), they were questioned on the quality of them. When asked how they would describe their Internet access, 55 percent $(n=29)$ of students responded that it was always reliable and fast, 12 percent $(n=6)$ claimed that it was always reliable, but slow, 31 percent $(\mathrm{n}=16)$ answered that it was sometimes unreliable, and two percent $(\mathrm{n}=1)$ said that it was always unreliable. We analysed these responses in relation to area of residence, and found that different areas throughout Perth seemed 
to have different levels of reliability and speed of the Internet. Students in the eastern metropolitan area $(n=6)$ appeared to have slower and less reliable Internet connections than average, with 33.5 percent having an always reliable and fast connection (as opposed to an average of 55 percent) and 50 percent having a connection that was sometimes unreliable (as opposed to an average of 31 percent). On the other hand, those in the southwest metropolitan area $(n=13)$ seemed to have faster and more reliable Internet connections than average. Here, 69 percent of students had an always reliable and fast connection, and 15.5 percent had a connection that was sometimes unreliable. Meanwhile, northern $(n=20)$ and central $(n=12)$ metropolitan areas had average levels of connectivity. Due to the extremely small number of students from the southeastern metropolitan area $(n=2)$, meaningful analysis of this area is impossible. However, ABS (2006, p.36) data suggests that this area is characterised by low connectivity. We found no correlation between lower SEIFA values and unreliable or slow Internet connections.

In regard to students' confidence using computers and the Internet, analysis by area of residence and SEIFA score generated some surprising results. In terms of students' SEIFA scores, a similar pattern appeared to that shown in self-assessed online participation. The confidence of students with computers and the Internet was inversely proportionate to the affluence of their suburb of residence, with less affluent suburbs containing students with higher levels of confidence. Again, there was a slight increase in confidence amongst those living in the most affluent suburbs. It is noteworthy that students living in areas with better connectivity, such as the southwest, tended to express lower levels of confidence when using computers and the Internet, while those living in areas with poorer connectivity, such as the east, had higher levels of confidence. These findings reflect our online participation findings, and could be partially explained by our earlier argument that the students who enrol in SmARTS are high-achieving and aspirational. These patterns in SEIFA scores and area of residence were also reflected in students' responses to the question "how easy or difficult did you find the SmARTS blog to use?"

The relationship between a student's residence and their ability to use the technologies required in SmARTS was more or less the opposite of what we anticipated. As expected, students' responses to the question regarding Internet connectivity showed that those in more affluent areas had faster and more reliable Internet connections. Thus, it seems desirable that, in future, SmARTS uses a blog that does not require a reliable, high speed Internet connection. However, contrary to our expectations, students with lower SEIFA scores and students living in less affluent geographical areas had the highest levels of online participation, had greater confidence with computers and the Internet, and claimed to use the blog with greater ease. These findings are contrary to those of previous researchers (Anderson, 2005, pp.175-6). However, our findings might be explained by the kinds of students who participate in the SmARTS program. Although some students may be from socio-economically disadvantaged areas, their parents seem willing to spend significant amounts of money (on the SmARTS program, for instance) in order for their children to receive a "good education" and extra-curricular experiences. Yet this does not explain why there appeared to be a slight increase in online participation, confidence, and ease using the blog amongst students with the highest SEIFA scores. In order to explain this finding, a larger number of student surveys would be desirable, as would a control group of students who are not participating in SmARTS (given that SmARTS students are not a true reflection of the year 11 student population). In addition to their area of 
residence, both the type of school a student attended and their gender are worth considering, with regard to the impact on their ability to use e-learning tools.

\section{Differences between students by school type}

Perth, and Australia in general, is characterised by a significant divide between public and private schools, which is the subject of much public debate. In 2008 in Western Australia, 59 percent of students were registered in public schools, while 40 percent were in private schools (Government of Western Australia Curriculum Council, 2009, p.5). In the second part of the 20th century, private schools began to receive significant amounts of government funding in Australia (Forsey, 2007, p.20). Although private schools had evolved alongside public ones, they had not previously received these funds (Forsey, 2007, p.20). To this day, the government funding of private schools remains a hotly debated topic throughout Australia (Forsey, 2007, p.20). In contemporary Western Australia, it has been recognised that private schools are gaining ascendancy over public ones (Forsey, 2007, p.13).

Alongside the division of private and public schools, according to Martin Forsey (2007, p.10), there exist "liberal fantasies of education as an unproblematic 'springboard for upward mobility'". Schools, both public and private, are commonly portrayed as allowing for the economic advancement of lower class students, rather being seen as locations where social inequalities are perpetuated (Forsey, 2007, p.10). The inequalities that exist between schools are evident in the league tables, which are released annually by The West Australian newspaper. These league tables measure the academic performance of schools throughout Western Australia (Forsey, 2007, p.78). Forsey $(2007$, p.78) states that, "while there are no set positions and schools do move up and down the tables from year to year, some stay consistently near the top while others are more often on the lower rungs". Here, we find a rural/urban divide as well as a public/private one (Forsey, 2007, p.26). Furthermore, schools located in affluent suburbs generally produce stronger examination results than those in less affluent areas (Forsey, 2007, p.26). While it is commonly assumed that all private schools are populated by affluent students, and it is true that schools that receive high rankings in the annual league tables are generally private, our findings suggest that there is a great deal of variation between private schools in regard to affluence.

As previously mentioned, the majority of students taking part in the SmARTS 2009 program came from private schools $(87 \%)$, while far fewer came from public schools $(13 \%)$. Of the 17 schools that took part, 11 were categorised as being among the top 50 Western Australian schools in 2008 (as categorised by the percentage of students receiving a TEE score of over 75) (Wood, 2009, p.12). Of these schools, ten were private and one was public. For our analysis, we divided schools into three groups. These were: top tier private schools, second tier private schools, and public schools. However, only eight public school students responded to the survey, in comparison to 18 top tier private school and 26 second tier private school students. Given the extremely small sample size of public school students, here we will compare only top tier and second tier private school students. While top tier private schools are extremely exclusive and affluent, second tier ones are generally less exclusive and are often located in areas quite far away from central Perth. In our discussion below, we will focus on inequalities between top and second tier private schools.

Our student surveys have shown that students who attended top tier private schools tended to live in suburbs with high SEIFA scores. Seventy percent $(n=7)$ of the 
students in the group with the highest SEIFA scores attended top-tier private schools (while the other $30 \%, n=3$, attended second-tier ones). Of the group with the lowest SEIFA scores, 100 percent $(n=6)$ attended second-tier private schools. The group of students with the second-lowest SEIFA scores contained a high proportion of second tier students, while the group with the second highest SEIFA scores contained a high proportion of top tier students. Thus, there is a fairly strong association between private school type and socioeconomic status, with students who live in relatively affluent areas also attending affluent schools.

In terms of the self-assessed participation of students in online tasks, there was a significant difference between top tier private $(n=18)$ and second tier private schools $(n=26)$. While 57.5 percent of second tier private school students said they regularly participated in online tasks, only 33 percent of top tier private school students made this claim. In addition, top tier private school students had the highest levels of occasional online participation $(50 \%)$, and second tier private school students had the lowest $(31 \%)$. The proportion of students who participated rarely was virtually identical between top and second tier private school students. These findings add weight to our hypothesis that SmARTS students who are not highly affluent may be more aspirational, or place a higher value on SmARTS as an opportunity, than those who are affluent. This may translate to higher levels of online participation. Indeed, it seems likely that less affluent parents, who are unable to afford top-tier private schooling for their children, might send them to less-expensive, second-tier private schools. This might help to explain the higher levels of participation evident amongst these students.

There appeared to be little difference in the reliability and speed of students' Internet connections when comparing school types. However, student surveys did uncover trends related to school type and confidence with technologies. Within top tier private schools, 50 percent of students said that they were always confident and 50 percent that they were mostly confident. In second tier private schools, 58 percent of students said they were always confident, 38 percent were mostly confident, and four percent said they were not confident. Therefore, it seems that second tier private school students have slightly higher levels of confidence with computers and the Internet than do top tier ones. Again, students' responses to the question "how easy/difficult did you find the blog to use?" showed similar findings, with second tier private schools students having fewer difficulties.

Tutor feedback on differences between schools was minimal, in part due to the fact that students often attended SmARTS sessions out of uniform, and therefore tutors were often unaware of which school their students attended. When asked if they had noticed any differences in student performance between schools, one tutor, Mary, responded that students had blended together fairly well (personal communication, 29 October 2009). However, later on in the interview, in response to a question about the frustrations she had experienced throughout the year, Cathy stated that, "actually going back to differences in schools I found, because I had four girls from, um [a top tier private school], they were in both of my groups and they did the least amount of work. And I don't know if that's just a coincidence, but they would always have an excuse - like boarding, and they couldn't access stuff" (personal communication, 29 October 2009). Thus, there was some discussion about differences between schools, although this was discussed on the level of individual schools, rather than in terms of 'school type'. 
Therefore, the type of school that a student attended appeared to have an impact on their access to and skills when using computers and the Internet. We found that although top tier private school students tended to live in more affluent suburbs, these students did not appear to have faster or more reliable internet connections than those attending second tier private schools. Self-assessed online participation showed that students attending second tier private schools had the highest participation rates. Second tier private school students were also slightly more confident with computers and the Internet, and had fewer difficulties with the SmARTS blogs. We will continue to collect data on parents' educational attainment and professions in order to discern why second tier private school students appear to do better. Finally, in considering inequalities and technological abilities, it is worth considering additional factors, such as gender.

\section{Gender: Are females disadvantaged by e-learning?}

The relationship between gender and technology has been extensively discussed by social theorists. Research suggests that women are "more comfortable with a relational, interactive, and connected approach to objects" and that men are more comfortable with adopting a "distanced stance, planning, commanding, and imposing principles" (Turkle \& Papert, 1990, p.150). Computer technologies have been traditionally envisioned as "masculine", and have been associated with rationality, control, domination, and instrumentality (Kirkup, 1992, p.277; Turkle \& Papert, 1990, p.150). Thus, it seems that the current social construction of computing privileges a style of thinking which may be repressive for many women (Kirkup, 1992, p.277). Given these arguments, it is important to question whether the computer and Internet technologies used in the SmARTS program are likely to advantage boys over girls, and whether there are likely to be differences in how boys and girls engage with these technologies.

Although these concerns should be considered, recent statistics suggest that there is increasing gender equality in computer and Internet access and use. Research conducted by the ABS (2004, p.8) found that, in their late school years (15-19 years) and in their early $20 \mathrm{~s}$, females are more likely to use the Internet than their male counterparts. However, higher rates of male access and use still exist amongst older Australians (ABS, 2004, p.8). Statistics from 2006 show that women aged between 25 and 54 had higher rates of access than their male counterparts, while men aged 55 and over had higher rates of access than their female counterparts (ABS, 2006, p.48). For those younger than 25, male and female access rates were relatively even (ABS, 2006, p.48). Furthermore, it has been observed that females in the school years six and ten are more proficient at using such technologies than are males (MCEETYA, 2007, p.60; MCEECDYA, 2010, p.39).

It remains questionable as to whether these statistics of access and use indicate that male control and dominance over computer and Internet technologies is decreasing. Of central importance is the question of whether these technologies continue to reflect and advocate masculine qualities, such as rationality, control, and instrumentality. However, popular opinion generally supports the notion that technologies are becoming increasingly "feminised". This notion is supported by the growing popularity of online shopping and socialising, both of which are viewed as traditionally feminine pursuits. However, in education and the workplace computers still appear to be largely dominated by males, particularly in relation to how they are used. 
Students' self-assessments, in regard to their online participation, revealed that female students ranked their participation higher. While 50 percent of female students claimed to participate regularly in online tasks, only 36 percent of male students said the same. Thus, participation seems to be slightly better amongst female students. This is particularly significant as there was a much higher dropout rate amongst male students, with 33 percent of all enrolling male students dropping out of SmARTS and only seven percent of all female students doing the same. When analysing students' survey responses, we found that there was little difference between males and females in regard to how confident they felt using computers and the Internet. We also found little difference between males and females in regard to how easy or difficult they found the SmARTS blog to use. Thus, there appears to be no gender differences in students' self-reported abilities when using computer and Internet technologies.

There was very little discussion of gender and technology amongst the SmARTS tutors, and no noticeable gender differences were identified by the tutors, in regard to the online component. The lack of differences found between male and female students, particularly in regard to their confidence with computers and the Internet and their experiences with the blogs, was somewhat unexpected. However, these findings support ABS (2004, p.8; 2006, pp.48-9) statistics that suggest the gender gap is closing when it comes to technology. Our observations suggest that there are no major differences between male and female students' computing and Internet skills.

\section{Conclusions}

Several conclusions can be drawn from our research findings. We found that students are not as tech-savvy as it is often assumed. In fact, it is usually more accurate to describe them as being tech-comfy. As we observed, many students, who we assumed were competent with computers and with navigating the Internet, simply "gave up" when they encountered technical problems with the blog.

Most importantly, our research highlights the importance of considering local context when employing e-learning methods. We discovered that the ways in which e-learning techniques are experienced by students were strongly influenced by Perth's levels of Internet and broadband connectivity, and students' differential access according to area of residence. In online interactions, we, as tutors, observed that students in some areas had less reliable or slower Internet connections. Gender did not appear, however, to have a significant impact.

We also found a link between the type of private school a student attended (top tier or second tier) and the SEIFA scores; that is, the top tier students came from higher socioeconomic areas than the second tier students. Interestingly, the second tier students participated more regularly and had fewer problems with navigating the online platforms. We suggest that the second tier students are more aspirational than the more affluent top tier students.

In the long-term, we hope to minimise any inequalities that exist between students when participating in the online component of SmARTS by selecting appropriate online platforms. As Carr-Chellman (2005a, p.258) argues, "we must seek ways to use technology for democratic ends that are sincere not only in their rhetoric but in their implementation. Such systems need to recognize... the inequalities that are too often perpetuated rather than redressed by their use". To achieve our aim, and in response to our findings, we introduced a new online platform, Posterous, in 2010. It is far easier 
to use, and since its implementation we have experienced no major technical problems. Furthermore, it does not require a series of passwords or multiple methods of communication, which have caused problems in the past. Anecdotally, it appears to be far quicker and more effective for computers with low speed or unreliable Internet connections. Finally, our findings highlight the need for universities to be aware of context when selecting a learning management system or running a unit with online components.

\section{References}

Anderson, B. (2005). New Zealand: Is online education a highway to the future? In A. A. CarrChellman (Ed.), Global perspectives on e-learning: Rhetoric and reality (pp.163-178). Thousand Oaks, CA: Sage Publications.

Australian Bureau of Statistics (ABS) (2004). Australia Online: How Australians are Using Computers and the Internet 2001 (No. 2056.0; R. Lloyd \& A. Bill).

http: / / www.abs.gov.au/AUSSTATS/abs@.nsf /DetailsPage/ 2056.02001?OpenDocument

Australian Bureau of Statistics (ABS) (2006). Patterns of Internet access in Australia 2006 (No. 8146.0.55.001; B. Pink). http: / / www.abs.gov.au / AUSSTATS/abs@.nsf/DetailsPage / 8146.0.55.0012006?OpenDocument

Australian Bureau of Statistics (ABS) (2008a). Australian Social Trends 2008 (No. 4102.0; B. Pink). http: / / www.abs.gov.au/AUSSTATS/abs@.nsf/DetailsPage/4102.02008?OpenDocument

Australian Bureau of Statistics (ABS) (2008b). Census of Population and Housing: Socio-Economic Indexes for Areas (SEIFA), Australia - Data Only, 2006 (State Suburb Code, Data Cube Only, 2006) (No. 2033.0.55.001). Canberra, Australian Capital Territory: Author. [viewed 18 May 2009] http:/ / www.abs.gov.au/AUSSTATS/abs@.nsf/DetailsPage/2033.0.55.0012006?OpenDocument

Australian Bureau of Statistics (ABS) (2009). Household Use of Information Technology 2008-09 (No. 8146.0; B. Pink). http: / / www.abs.gov.au/ AUSSTATS/ abs@.nsf/DetailsPage/8146.0200809? OpenDocument

Australian Bureau of Statistics (ABS) (2010). Population Estimates by Statistical Local Area, 2001 to 2009 (No. 3218.0). [viewed 18 May 2009]. http: / / www.abs.gov.au/AUSSTATS/abs@.nsf/DetailsPage/3218.02008-09

Carr-Chellman, A. A. (2005a). Conclusions. In A. A. Carr-Chellman (Ed.), Global perspectives on elearning: Rhetoric and reality (pp.257-259). Thousand Oaks, CA: Sage Publications.

Carr-Chellman, A. A. (2005b). Introduction. In A. A. Carr-Chellman (Ed.), Global perspectives on elearning: Rhetoric and reality (pp.1-16). Thousand Oaks, CA: Sage Publications.

Clegg, S., Hudson, A. \& Steel, J. (2003). The emperor's new clothes: Globalisation and e-learning in higher education. British Journal of Sociology of Education, 24(1), 39-53. http:/ / www.ingentaconnect.com/content/routledg/cbse/2003/00000024/00000001/art00003

Department of Education (2011). Alphabetical list of Western Australian Schools. [viewed 18 May 2011] http:/ / www2.eddept.wa.edu.au/dev60cgi/sdrrwcgi.exe?sdr0880

Forsey, M. (2007). Challenging the system? A dramatic tale of neoliberal reform in an Australian high school. Charlotte, NC: Information Age Publishing.

Government of Western Australia Curriculum Council (2009). 2008 External assessment and examinations report. [viewed 2 May 2011] http:/ / www.curriculum.wa.edu.au/internet/Publications / Reports / Statistical_Reports

Hargittai, E. (2002). Second-level digital divide: Differences in people's online skills. First Monday, 7(4). http:/ / firstmonday.org/htbin/cgiwrap/bin/ojs/index.php/fm/article/view/942/864

Kennedy, G. E., Judd, T. S., Churchward, A. \& Gray, K. (2008). First year students' experiences with technology: Are they really digital natives? Australasian Journal of Educational Technology, 24(1), 108-122. http:/ / www.ascilite.org.au/ajet/ajet24/kennedy.html 
Kirkup, G. (1992). The social construction of computers: Hammers or harpsichords? In G. Kirkup \& L. S. Keller (Eds.), Inventing women: Science, technology and gender (pp.267-281). Cambridge, MA: Polity Press.

Liu, G. \& Hwang, G. (2009). A key step to understanding paradigm shifts in e-learning: Towards context-aware ubiquitous learning. British Journal of Educational Technology, 41(2), E1-E9. DOI: $10.1111 /$ j.1467-8535.2009.00976.x

Ministerial Council for Education, Employment, Training and Youth Affairs (MCEETYA). (2007). National assessment program - ICT literacy Years 6 and 10 Report, 2005. [verified 27 May 2011] http:/ / www.nap.edu.au/_Documents/MCEECDYA/2005\%20ICTL\%20Public\%20Report.pdf

Ministerial Council for Education, Early Childhood Development and Youth Affairs (MCEECDYA) (2010). National assessment program - ICT literacy Years 6 and 10 Report, 2008. [verified 27 May 2011] http:/ / www.mceecdya.edu.au/verve/_resources/NAP-ICTL_2008_report.pdf

Pegrum, M. (2009). From blogs to bombs: The future of digital technologies in education. Crawley, Australia: UWA Publishing.

Postman, N. (1993). Technopoly: The surrender of culture to technology. New York: Vintage Books.

Rettberg, J. W. (2008). Blogging. Cambridge, UK; Malden, MA: Polity Press

Sassen, S. (2004). Towards a sociology of information technology. In C. Avgerou, C. Ciborra, \& F. Land (Eds.), The social study of information and communication technology: Innovation, actors, and contexts (pp.77-99). Oxford, UK; New York: Oxford University Press.

Scott, A., Semmens, L. \& Willoughby, L. (2001). Women and the Internet: The natural history of a research project. In E. Green \& A. Adam (Eds.), Virtual gender: Technology, consumption and identity (pp.3-27). London; New York: Routledge.

Turkle, S. \& Papert, S. (1990). Epistemological pluralism: Styles and voices within the computer culture. Signs: Journal of Women in Culture and Society, 16(1), 128-157. [verified 27 May 2011] http: / / leavesofthetree.files.wordpress.com/2010/07/turkle_signs.pdf

University of Western Australia (UWA) (2010). Faculty of Arts, Humanities and Social Sciences: SmARTS. [viewed 26 May 2011] http:/ / www.arts.uwa.edu.au/community/smarts

White, K., Shade, L. R. \& Brayton, J. (2001). Lives and livelihoods in the technological age. In E. Green \& A. Adam (Eds.), Virtual gender: Technology, consumption and identity (pp.45-62). London; New York: Routledge.

Wood, D. (2009). Year 12 school data 2008. Curriculum Council. [viewed 18 May 2011] http: / / www.curriculum.wa.edu.au/internet/_Documents/Statistics/School+achievement+ data $+2008+$ full + file.pdf

Authors: Dr Nicole Crawford, University Preparation Program University of Tasmania, Launceston TAS 7250, Australia

Email: nicole.crawford@utas.edu.au

Lara McKenzie, Faculty of Arts, Humanities and Social Sciences The University of Western Australia, Crawley WA 6009, Australia

Email: mckenl01@student.uwa.edu.au

Please cite as: Crawford, N. \& McKenzie, L. (2011). E-learning in context: An assessment of student inequalities in a university outreach program. Australasian Journal of Educational Technology, 27(3), 531-545.

http:/ / www.ascilite.org.au/ajet/ajet27/ crawford.html 